\title{
Post-acute integration strategies in an era of accountability
}

\author{
John P McHugh' ${ }^{1}$, Amal N Trivedi ${ }^{1,2}$, Jacqueline S Zinn ${ }^{3}$, Vincent Mor ${ }^{1,2}$ \\ 1. Brown University School of Public Health, Providence, United States. 2. Providence Veterans Administration Medical \\ Center, Providence, United States. 3. Fox School of Business, Temple University, Philadelphia, United States.
}

Correspondence: J ohn P McHugh. Address: Brown University School of Public Health, 121 S Main Street, Box GS-121-2, Providence, RI 02912, United States. E-mail: john_mchugh@brown.edu

Received: August 5, 2014

Accepted: September 24, 2014

Online Published: October 20, 2014

DOI : $10.5430 /$ jha.v3n6p103

URL: http://dx.doi.org/10.5430/jha.v3n6p103

\begin{abstract}
The Institute of Medicine, in its 2001 Crossing the Quality Chasm report, recommended greater integration and coordination as a component of a transformed health care system, yet relationships between acute and post-acute providers have remained weak. With payment reforms that hold hospitals and health systems accountable for the total costs of care and readmissions, the dynamic between acute and post-acute providers is changing. In this article, we outline the internal and market factors that will drive health systems' decisions about whether and how they integrate with post-acute providers. Enhanced integration between acute and post-acute providers should reduce variation in post-acute spending.
\end{abstract}

\section{Key words}

Skilled nursing, Hospitals, Post-acute, Readmissions

\section{I ntroduction}

In its 2001 Crossing the Quality Chasm report, the Institute of Medicine (IOM) recommended increased integration and coordination of care as one way to improve the quality of care ${ }^{[1]}$. This would "address the need to manage smooth transitions from one setting to another or from a health care to a self-care setting”. Despite this recommendation, the continued use of fee-for-service payments incentivized health care providers to maximize the volume and intensity of services rather than enhance coordination or reduce the costs of post-discharge care. As a result, relationships across the continuum of care and especially between acute and post-acute providers have remained weak ${ }^{[2]}$.

Hospital administrators primarily focused on the patient's experience and outcomes from admission until discharge from their institution ${ }^{[2]}$. There was minimal coordination across unaffiliated institutions and, to date, little incentive to implement it. Furthermore, most hospital-based health systems focused (and still focus) on maximizing the referral base of hospital admissions through acquisition of outpatient physician practices ${ }^{[3]}$ which has a much more direct return on investment in the current fee-for-service reimbursement environment, compared to integration with post-acute resources.

The Affordable Care Act (ACA) has forced providers to contemplate the care a patient receives for the 30, 60 or even 90 days post-discharge through readmission penalties, bundled payment models and total cost of care measures. In this article, we examine a framework within which health systems can think about how they relate to post-acute providers. First we 
will provide background on the changing dynamics, both financial and organizational, to catalyze change. Then we will discuss internal and market-level factors that likely guide health systems' decisions about their interactions with post-acute providers.

\section{Evolving attitudes toward post-acute care}

\subsection{Policymakers are focused on post-acute spending}

In the June 2007 MedPac report to Congress, hospital readmissions were identified as a substantial and potentially avoidable cost ${ }^{[4]}$. Specifically, "the failure to adequately attend to the care transition at discharge from the hospital results in additional Medicare spending; 17.6 percent of admissions result in readmissions within 30 days of discharge, accounting for $\$ 15$ billion in spending. Not all of these readmissions are avoidable, but some are”. The report goes on to outline a two-step process to reduce readmissions, starting with public reporting and transitioning to new payment methodologies.

The first of the payment methodology changes, readmission penalties, went into effect on October 1, 2012. According to some reports ${ }^{[5]}$, the first seven years of readmission penalties could save Medicare up to $\$ 8.2$ billion. However, with a relatively meager average penalty of only $\$ 125,000$ per hospital, there is still little financial incentive to dedicate significant resources to post-acute investments.

\subsection{Financial risk outside the hospital walls}

Penalties can reduce overall health system costs by motivating practice changes to reduce readmissions, but additional incentives are necessary to materially affect quality. Specifically, according to the Centers for Medicare and Medicaid Services (2013), hospitals must have more financial risk/incentives to drive more systematic change ${ }^{[6]}$.

Within the post-acute care sector, one integration catalyst may be the Medicare Spending per Beneficiary (MSPB) measure recently endorsed by CMS. The MSPB Measure assesses the cost of services performed by hospitals and other healthcare providers during an MSPB hospitalization episode, which comprises the period immediately prior to, during, and following a patient's hospital stay ${ }^{[6]}$. By putting the total cost of care from the inpatient stay to 30 days post-discharge at risk, health systems will need to reevaluate the discharge planning process, which will include the resources devoted to coordination with post-acute care providers.

\subsection{Health systems are not structured for financial risk}

Health systems developed in large part to take advantage of economies of scale, but had limited incentives to operate in a truly integrated fashion. Recent and proposed payment system changes are catalyzing health systems to move from confederations of hospitals to clinically integrated networks across the continuum of care. According to a Cain Brothers report (2012), hospitals can no longer passively discharge patients to post-acute providers, but must become accountable for quality and resource control in the post-discharge period ${ }^{[7]}$.

Change of this magnitude in medical care financing requires a parallel change in the organizational structure of health systems. The vast majority of health systems are not structured to accept financial risk for the total costs of care, yet a 2013 Advisory Board survey found that the percentage of hospitals accepting such risk-based contracts rose from 14\% in 2011 to $35 \%$ in $2013^{[8]}$. There was also an increase from $16 \%$ to $27 \%$ in the percentage of hospitals adopting bundled payment contracts. The survey report goes on to state, "the trend toward greater provider accountability is not likely to abate". The emergence of accountable care organizations, bundled payments and other payment reforms will drive the change desired by the IOM, increased integration and coordination, and will also drive organizational changes to manage risk and care transitions. 


\section{Broadening the definition of the health system}

\subsection{Health systems started with physician practice acquisitions}

Integrating continuum of care components is not new to acute providers, as the "upstream” market for purchasing medical practices has been very active ${ }^{[3]}$. However, "upstream” integration has a much greater financial benefit than coordination of care for patients after discharge even though that is where the risk is now located. Acquisition of post-acute resources is different from acquiring physician practices in several ways.

First, physician practices are sufficiently localized, meaning an acute provider is acquiring an entire practice with local authority in the negotiation process. On the other hand, post-acute providers are frequently parts of larger national chains, which can have an entirely different, and often more complicated, acquisition cost associated with them. Second, postacute care exists along an evolving continuum, often with independent organizations providing the different services (home health, long-term care, skilled nursing, independent rehabilitation), meaning acute providers must think through their strategic position regarding each service type and how patients transition through each. Third, the financial reward, in a fee-for-service model, associated with acquiring post-acute assets is limited as compared to the potential upside of a primary care practice referring new inpatient volume to a facility. Fourth, post-acute provider acquisition carries with it substantial fixed asset risk, since the "bricks and mortar" are likely to have greater bed capacity than the hospital needs to ensure high quality discharges of its patients. Finally, few, if any, health systems have core competency in the post-acute space.

While acquisition of primary care practices differs from post-acute, “upstream” integration will remain fundamental in reducing post-acute costs, as both primary care and post-acute resources are essential components of a clinically integrated network ${ }^{[9]}$.

\subsection{Hospitals are not enough}

Many health systems are still simply confederations of hospitals and their investments have focused on acquiring “upstream” ambulatory care providers. The ambulatory networks exist to expand a health system's market presence and, ultimately, to fill beds. If maximizing inpatient revenue is the primary goal, there is no need to integrate with post-acute providers. In other words, a relationship with a post-acute provider would not enhance market strength or mitigate financial risk.

Payment reform has changed the equation. Health systems now bear financial risk for the total cost of care post-discharge and reputational risk through public reporting of readmission rates. As a result, despite hospital's best efforts to push back ${ }^{[10]}$, the definition of the health system has changed and in turn the decision process regarding investment in post-acute assets. If a hospital is at risk for the total cost of care 30 days post-discharge or incurs a readmission penalty, the cost-benefit of where the hospital focuses attention materially changes. Now, the quality of the post-acute provider matters, as does the hospital's level of integration and coordination with the post-acute provider. As a result, many providers are contemplating vertical integration into the post-acute landscape ${ }^{[2]}$.

\subsection{Post-acute providers preparing for integration}

In a May 2013 report from Sawgrass Partners, LLC entitled “Developing Successful Hospital Partnerships”, the authors outline specific strategies for skilled nursing facilities to partner with hospitals ${ }^{[11]}$. They first suggest each skilled nursing facility (SNF) assess its own internal readiness for a hospital partnership. Of the key areas to address in the readiness assessment, they include:

- $\quad$ Assessment of strategic opportunities with local hospitals

- $\quad$ Access to funding for IT improvements and connectivity 
- Inventory of physician relationships

- Assessment of clinical care programs

- $\quad$ Continuum of care service offerings

- Organizational structure and leadership capabilities

- Historical readmission rates and current clinical outcomes

As post-acute providers prepare for and seek out more integrated partnerships, hospitals that are not prepared to act may be left with a portfolio of lower quality providers. While historically, post-acute providers could have been described as more "passive" participants in the continuum of care due partly to a lack of financial risk, the implementation of the readmission penalty, even though initially just for hospitals, has changed the dynamic for all participants.

\subsection{Lessons from the auto industry}

Vertical integration has been a strategic component of most business models in industries defined by complex systems. In the auto industry, research by Monteverde and Teece (1982) ${ }^{[12]}$ hypothesized that "assemblers will vertically integrate when the production process, broadly defined, generates specialized, non-patentable know-how". They further state that "the existence of transaction-specific know-how and skills and the difficulties of skill transfer mean that it will be costly to switch to an alternative supplier”. In order to maximize profit, auto makers are at risk for the total cost of production. As a result, the auto makers will vertically integrate if the complexity of a production process for a component provides the supplier with an "exploitable first-mover advantage". Monteverde and Teece (1982) go on to state, "clearly, design and implementation for any system as complex as an automobile must be tightly coordinated". As the transaction cost increases, the level of integration must increase to the tipping point where the "make" versus "buy" decision is made.

There is one very big distinction to be made between the auto industry and the health care system. The supplier, in this case the post-acute provider, cannot exert pricing pressure on the hospital, because they do not have control over price, which is set be CMS. Therefore, the transaction cost in an acute/post-acute referral is related to the coordination of efforts required for the transition, as well as the contract management costs if the hospital decides against full integration. That is, developing systems and processes and possibly contractual obligations to stay connected to a patient post-discharge requires both financial and human capital.

Hospitals have the necessary information at discharge to evaluate the complexity of patients in regards to their risk of readmission ${ }^{[13]}$, yet our healthcare system, on average, has been far from tightly coordinated. As a result, there are missteps and errors in patient care, especially for those with complex medical needs ${ }^{[14]}$. If health care were to learn from the auto industry, then the level of coordination and integration should increase as the complexity of the patient (and thus the transaction cost) increases, thus influencing a hospital's decision process related to its relationship with post-acute providers.

\subsection{Form follows function}

One reason that the health care industry has been slower to adopt more coordinated care has been the traditional feefor-service approach to payment. With limited focus on quality-based financing, hospitals have had little incentive to differentiate based on quality of patient experience outside the hospital.

Structurally, the traditional incentives have created governance and operational models which are institution and finance centric. A survey by Jha and Epstein (2010) found that, on average, in 2007-2008, quality performance was on the agenda at board meetings $63 \%$ of the time while financial performance was on the agenda $93 \%$ of the time ${ }^{[15]}$. Health systems are structured to gain access to new referrals, rather than focusing on improving the health of a population and/or reducing the total cost of care across the continuum. 
Payment reform has merged finance and quality through a focus on accountability. Accountable Care Organizations (ACOs), bundling and risk contracting will force institutions to expand their operating models outside the walls of the hospital and consider the care transitions along the continuum which can often add undue cost and negatively affect quality. This is leading to more integrated approaches to post-acute care. Research has shown that even in the absence of an explicit preferred provider network, hospitals that concentrate their discharges on select SNFs can demonstrate better quality via reduced readmissions ${ }^{[16]}$.

\section{Mechanisms to control the total cost of care}

\subsection{Transitions of care considerations}

Controlling the cost of care involves more tightly integrated transitions of care. Most research on this subject addresses discharge from hospital to home ${ }^{[14]}$, yet many of the same principles can be extrapolated to the hospital to post-acute transition. In a January 2014 report on Care Transitions from the Center for Healthcare Research and Transformation ${ }^{[17]}$, a partnership between the University of Michigan and Blue Cross/Blue Shield of Michigan, the author summarizes the following best practices in care management:

- $\quad$ Comprehensive discharge planning

- Complete and timely communication of information

- $\quad$ Medication reconciliation

- Patient/care giver education using the "teach back" method

- Open communication between providers

- $\quad$ Prompt follow-up visit with an outpatient provider after discharge

In addition to the above list, when considering discharge from hospital to SNF, it is important for hospitals to know the PAC providers' readmission rates.

\subsection{One size does not fit all}

Following the model of the auto industry, the institutions that should consider a tightly integrated approach to post-acute care would be those with higher transaction costs; discharging more complex patients who pose the greatest risk for a readmission or other costly post-acute events. These patients will require more coordination across institutions and more caregiver involvement, perhaps, even an inter-disciplinary team of physicians and care managers.

Jeff Goldsmith (2011) wrote about the case for flexible partnerships between health plans and providers, considering three types of health services; primary medical care, unscheduled care, and specialty care ${ }^{[18]}$. A similar analogy can be made in looking at integrating post-acute resources, where the complexity of the patient population drives the level of investment required. Hospitals are left with three primary strategies (which are not mutually exclusive):

- Steering: consolidating referrals to higher quality providers

- Bundling: establishing a contractual partnership with mutual obligations

- Integrating: buying or building a SNF or home health care network

Health systems can implement one or several of these strategies. Some examples of health system/post-acute coordination strategies include: 


\section{- Altrius Health (Eastern/Central, MA) - Steering (Preferred Partner) ${ }^{[19]}$}

In 2012, Altrius created a preferred network of skilled nursing facilities to improve coordination of care. The goals of the network were to improve communication and sharing of information between the SNFs and the primary care physicians to reduce SNF length of stay and readmissions. The selection process included the following criteria: location of care, facility rating, facility attributes, willingness to collaborate, and value to patient. After visiting more than 100 facilities, Altrius narrowed their preferred network to about 50 SNFs. Readmission rates for Altrius patients sent to SNF decreased from 12\% in 2012 to $8.7 \%$ in 2013, resulting in just under $\$ 1 \mathrm{M}$ in savings.

\section{- $\quad$ Geisinger Health System (Danville, PA) - Bundling ${ }^{[20]}$}

Geisinger has developed a ProvenHealth medical home model which bundles services for patients within their system. The medical neighborhood includes “ $360^{\circ}$ care systems” for SNF, Home Health, Inpatient Hospital, and ED. As part of the effort to improve communication with nursing homes, the ProvenHealth model includes daily presence of advanced nurse practitioners in nursing homes.

\section{- ProMedica/ManorCare (Toledo, $\mathrm{OH})$ - Integration (joint venture) ${ }^{[21]}$}

ProMedica and ManorCare signed a collaborative agreement to build a preferred provider, joint venture skilled nursing and rehabilitation center. The facility will be built on one of ProMedica's campuses. One of the key provisions is forming a quality committee with clinical staff from both institutions. The collaboration is intended to reduce preventable and unnecessary rehospitalizations and improving both patient care and satisfaction.

\section{- Partners Health Care (Boston, MA) - Integration (full ownership) ${ }^{[22,23]}$}

Partners Health Care has chosen the full integration model in which post-acute resources are combined within a separate corporate entity with management control and responsibility for total range of post-acute services. The organization utilizes the 4NEXT web-based system to support transitions of care from acute to post-acute.

Each of the strategies help to control the total cost of care, but have varying levels of transaction cost requirements based on several key criteria including; patient complexity, the useful life of the asset, the cost of errors, and market-specific considerations. Each of these is described in more detail below.

\subsubsection{Patient complexity}

The complexity of the patient is the first consideration for a hospital or health system looking to integrate with a post-acute partner. Institutions discharging patients with greater complexity will require greater coordination, as the transaction cost of the transfer increases ${ }^{[13]}$. Hospitals with low levels of patient complexity, while still requiring communication across sites, do not necessarily have to be integrated in a tightly coordinated manner.

\subsubsection{Useful life of the asset}

In the decade after introduction of SNF prospective payment system (PPS), the number of hospital-based SNFs dropped from about 2,500 to about 1,000, since hospital-based SNF costs were generally much higher than SNF PPS rates ${ }^{[24]}$. As a result, hospitals and health systems will cautiously pursue a full integration post-acute strategy. Furthermore, with care increasingly moving to lower cost settings, and post-acute care situated along a continuum, most predictions expect a continued trend toward home health or other lower cost post-acute providers. If a hospital or health system has barely enough volume today to fill a SNF, they will be left with an underutilized asset as more of their discharges go to less costly settings, or a SNF with a moderate to large percentage of inappropriate admissions which do not provide adequate financial return. This, again, points to the level of complexity of the discharged patient. Those institutions with a high volume of complex patients are better positioned to have a longer-term trajectory of referrals to the SNF setting, although ownership will necessarily continue to present financial challenges since hospital based SNF costs historically are much higher than free-standing facilities. 


\subsubsection{Costs of errors}

The second consideration is the reputational and fiscal cost of an error. In a highly competitive market, a significantly higher readmission rate could affect the overall performance of a hospital or health system as payers, employers and even patients begin to make more informed choices about who is in their network or with whom to contract. Additionally, payment reform and risk contracts will have a direct influence on the decision process. Hospitals with greater accountability for the total cost of care will pursue post-acute partners differently, but should not lose sight of the long-term trajectory of the asset.

\subsubsection{Market-specific considerations}

Each provider will have market-specific considerations related to the SNF bed supply and quality of the local post-acute providers. In a market with relatively lower levels of SNF capacity, a health system may prefer to acquire beds in order to guarantee access, unless the contractual situation includes some level of access guarantee. In markets with oversupply or consolidation of assets, the preference would most likely be to contract for an established "partnership", as long as the quality of the provider is sufficient (see the figure).

Figure. Conceptual framework of post-acute integration options based on market conditions and health system/hospital characteristics

Source: Authors’ conceptual framework

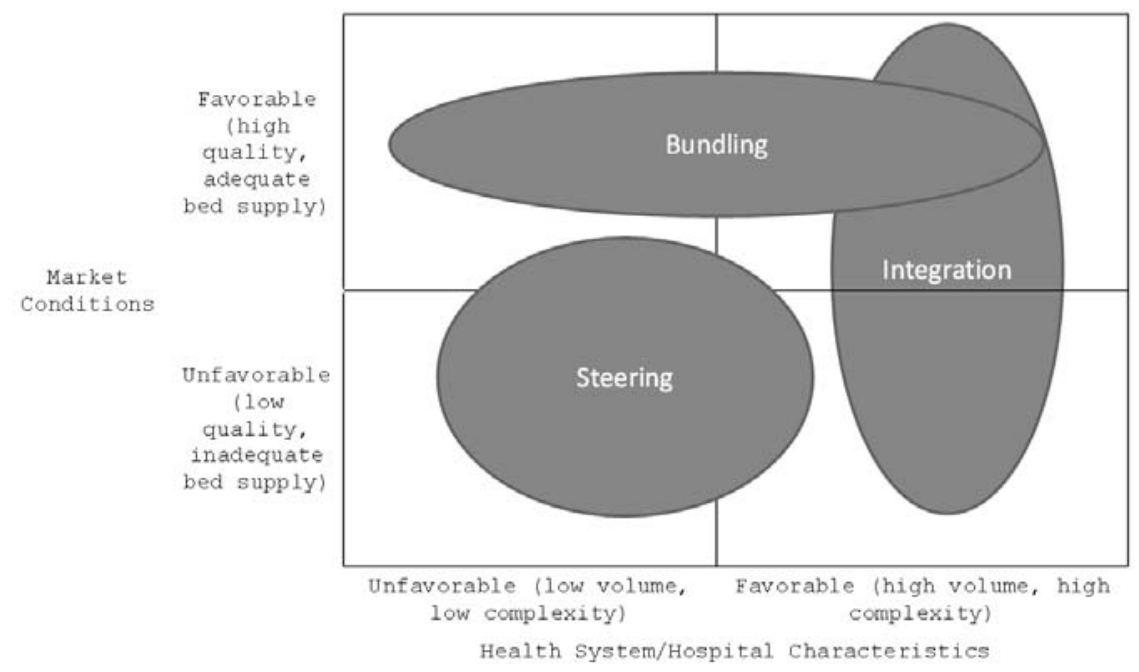

Bed supply and quality often go hand in hand, as higher volume SNFs demonstrate lower readmission rates ${ }^{[25]}$. Regardless, if there is adequate quality in the market, the effort to own beds and duplicate supply would be wasteful, and the decision should more often be to contract for access or develop preferred networks. If the post-acute providers are lower tier ${ }^{[26]}$, the hospital would need to exert more control over the provider to ensure improvements, which may translate into the need to establish an ownership situation.

Based on the decision framework criteria, the providers that should be considering the integrated solution are those that have high transaction costs most likely characterized by high volumes of complex patients discharged from their facilities.

Smaller volume hospitals most likely do not have the volume necessary to sustain a SNF under an integrated or even bundled arrangement. However, these facilities could consider steering referrals either independently or as part of a broader ACO framework in order to reduce readmission rates and the total cost of care.

\subsection{Potential barriers}

There are several potential barriers to post-acute care integration. First, any partnership arrangement must meet the requirements in the federal anti-kickback statutes. "The Office of the Inspector General views joint ventures in particular as susceptible to fraud and abuse if the parties are in a position to make or influence referrals directly or indirectly to the other party or the jointly held company” ${ }^{[27]}$. Stark regulations, depending on the arrangement, will change the transaction 
costs associated with referrals to an independent entity. Thus, a hospital or health system may choose an acquisition so as to mitigate the regulatory risk.

Additionally, patients demand choice in their healthcare decisions. Preferred provider network may limit patients' choice of post-acute provider. However, if the decision framework is aligned with optimal outcomes, then patients that are "steered" to preferred providers may be willing to forego choice for documented superior quality.

While the Deficit Reduction Act of 2005 led to the development and demonstration of the Community Assessment Record and Evaluation (CARE) Item Set ${ }^{[28]}$, the tool is not yet widely utilized. Therefore, it is costly to coordinate efforts across multiple post-acute providers. Implementation of the CARE tool, or similar common assessment systems, could help to reduce the overall transaction costs to the acute providers.

Most hospitals do not have the analytical expertise to adequately assess which SNFs in their particular market provide higher quality care and minimize 30-day post-acute costs. Additionally, hospitals and post-acute providers may not have integrated clinical information systems that allow electronic medical records to be seamlessly integrated across sites. This can lead to medical errors, such as problems with medication reconciliation or sharing results of imaging and/or laboratory test results.

A final barrier is one of post-acute readiness. Many post-acute providers do not have the internal capabilities to execute a more coordinated strategy with an acute partner. Furthermore, if the post-acute market is fragmented across the continuum, the hospital will have to manage multiple relationships with individual components, again increasing the transaction cost of coordination.

\section{Discussion}

Payment reform has changed the nature of acute/post-acute relationships. Historically, acute providers have focused on care that occurs within their institution, such as reducing length of stay. Patients were often discharged to postacute providers with minimal, if any, coordination with complex patients often suffering adverse consequences after discharge ${ }^{[29]}$. Focus on accountability and the total cost of care, including post-discharge care, alters the dynamic, catalyzing the necessary structural changes to manage care transitions and financial risk through tighter integration with post-acute providers.

Li et al. (2012) demonstrated improved quality, as measured by reduced readmissions, at higher volume SNF providers ${ }^{\text {[25] }}$. While they did not distinguish between "practice makes perfect" or "selective referrals" as the primary cause, it should not matter to a hospital considering a more tightly coordinated relationship. Rahman et al. further demonstrated that concentrating referrals to a select number of post-acute providers can improve quality through reduced readmissions ${ }^{[16]}$. Given the implementation of PPACA, readmission penalties, and payment reforms, hospitals and health systems are looking at their post-acute relationships differently.

A transaction cost decision process to preferred provider networks should help hospitals to make the optimal choice to minimize cost and maximize quality outcomes. Hospitals and health systems with adequate volumes of complex patients will most likely pursue integration via tightly managed contracts or acquisition of post-acute resources. Those with less complex discharges will most likely seek concurrent strategies in which they will seek preferred providers for high complexity patients which may involve contractual relationships and referring the remaining patients to high quality (or best available) providers with less coordinated solutions.

The ACO framework could be a mechanism for preferred providers, as those providers, in particular, are most likely to have the ability to accept risk within the ACO framework or even within a bundled payment initiative. This may also 
provide smaller hospitals with a structure in which they can consolidate referrals without many of the additional costs associated with managing a post-acute network.

Upon first blush, many providers may see integration of a post-acute provider via acquisition as a necessary step to reduce readmission. However, the decision process must take a longer term view and consider the useful life of the asset and the transaction costs required based on the types of patients discharged from the facility (or network of facilities for a system). This will leave many providers with the ultimate decision to simply consolidate referrals by selecting a number of high quality providers, rather than taking on the risk of owning another institutional asset which has a limited useful life as volume continues to shift to lower cost post-acute settings.

\section{Conclusion}

The Affordable Care Act has forced health systems to broaden their span of control and focus to include post-acute providers. CMS-initiated payment reforms will motivate hospitals to integrate with post-acute providers to reduce postdischarge costs and improve the quality of care. With more coordination between acute and post-acute providers, from simple steering to more complex integration strategies, health systems have the potential to reduce variation in post-acute spending and reduce costly readmissions.

\section{Acknowledgements}

This work was supported by the National Institute on Aging grants P01AG027296 (PI: Vincent Mor).

\section{Disclosures}

The authors have no relevant disclosures to declare for this study.

\section{References}

[1] Institute of Medicine (IOM). Crossing the Quality Chasm: A New Health System for the 21st Century. Washington, D.C: National Academy Press. 2001.

[2] Hospitals \& Health Networks. Lola Butcher. Hospitals strengthen bonds with post-acute providers. 2013. Available from: http://www.hhnmag.com/display/HHN-news-article.dhtml?dcrPath=/templatedata/HF_Common/NewsArticle/data/HHN/Magaz ine/2013/Jan/0113HHN_Feature_strategy

[3] Robert Kocher, MD, Nikhil R Sahni, BS. Hospitals’ Race to Employ Physicians - The Logic Behind a Money-Losing Proposition. New England Journal of Medicine. 2011; 364: 19. PMid: 21449774. http://dx.doi.org/10.1056/NEJMp1101959

[4] Medicare Payment Advisory Commission. Report to the Congress: Promoting Greater Efficiency in Medicare. Washington, DC: MedPAC. June 2007. Available from: http://www.medpac.gov/documents/jun07_entirereport.pdf

[5] Commonwealth Fund Blog. Mara Laderman, MSPH, Saranya Loehrer, MD, MPH, Douglas McCarthy, MBA, Institute for Healthcare Improvement. The Effect of Medicare Readmissions Penalties on Hospitals' Efforts to Reduce Readmissions: Perspectives from the Field. 2013. Available from: http://www.commonwealthfund.org/publications/blog/2013/feb/the-effect-of-medicare-readmissions-penalties-on-hospitals

[6] Centers for Medicare and Medicaid Services. Measure Information Form: Measure ID - MSPB-1. 2013. Available from: http://www.qualitynet.org/dcs/ContentServer?c=Page\&pagename=QnetPublic\%2FPage\%2FQnetTier4\&cid=1228772057350

[7] Bill Pomeranz, Wyatt Ritchie. Integrating Acute and Post-Acute Care: The Emerging Merging of the Sectors. Cain Brothers: Strategies for Healthcare Leaders. 2012. Available from: http://www.baylorqualityalliance.com/news/Documents/Integrating\%20Acute\%20Post-Acute\%20Care\%20-\%20The\%20Emerg ing\%20Merging\%20of\%20the\%20Sectors.pdf

[8] Advisory Board Company. Jordan Stone. Survey results: Percentage of providers taking on risk doubled since. 2011. Available from: http://www.advisory.com/Research/Health-Care-Advisory-Board/Blogs/Toward-Accountable-Payment/2013/05/Accountable-p ayment-survey 
[9] Sharon Silow-Carroll, Jennifer N Edwards, Aimee Lashbrook. Commonwealth Fund. Health Management Associates. 2011. Reducing Hospital Readmissions: Lessons from Top-Performing Hospitals. The Commonwealth Fund: Synthesis Report. Available from: http://www.commonwealthfund.org/publications/case-studies/2011/apr/reducing-hospital-readmissions

[10] Janet Adamy. WellPoint Shakes Up Hospital Payments. Wall Street Journal. Available from: http://online.wsj.com/news/articles/SB10001424052748704281504576325163218629124. 2011.

[11] Sawgrass Partners, LLC, Michael Logan, MHA. Developing Successful Hospital Partnerships. Available from: http://www.sawgrasspartners.com/pdf/SawgrassPartnersWhitePaper-DevelopingSuccessfulHospitalPartnerships-MikeLogan.pdf. May 2013.

[12] Kirk Monteverde, David J Teece. Supplier Switching Costs and Vertical Integration in the Automobile Industry. The Bell Journal of Economics. Spring 1982; 13(1): 206-213. http://dx.doi.org/10.2307/3003441

[13] Eric A Coleman, Sung-joon Min, Alyssa Chomiak, Andrew M Kramer. Posthospital Care Transitions: Patterns, Complications, and Risk Identification. HSR: Health Services Research. October 2004; 39: 5.

[14] Eric A Coleman, MD, MPH, Sandra Chalmers, MPH. The Care Transitions Intervention. Arch Intern Med. 2006; 166(25): 1822-1828. PMid: 17000937. http://dx.doi.org/10.1001/archinte.166.17.1822

[15] Ashish Jha, Arnold Epstein. Hospital Governance and the Quality of Care. Health Affairs. 2010; 29(1): 182-187. PMid: 19897509. http://dx.doi.org/10.1377/hlthaff.2009.0297

[16] Rahman, M., Foster, A. D., Grabowski, D. C., Zinn, J. S., Mor, V. Effect of Hospital-SNF Referral Linkages on Rehospitalization. Health Services Research. 2013; 48: 1898-1919. PMid: 24134773. http://dx.doi.org/10.1111/1475-6773.12112

[17] Theresa Dreyer, MHA. Center for Healthcare Research and Transformation. Care Transitions: Best Practices and Evidence-Based Programs. Available from: http://www.chrt.org/assets/policy-papers/CHRT-Care-Transitions-Best-Practices-and-Evidence-based-Programs.pdf. 2014.

[18] Jeff Goldsmith. Accountable Care Organizations: The Case for Flexible Partnerships Between Health Plans and Providers. Health Affairs. 2011; 30(1): 32-40. PMid: 21209435. http://dx.doi.org/10.1377/hlthaff.2010.0782

[19] Linda Oliver, PA-C, MPH. Building a Preferred Skilled Nursing Facility Network. Altrius Health. Available from: http://blog.atriushealth.org/building-a-preferred-skilled-nursing-facility-network/

[20] Janet Tomcavage, RN, MSN. Post-Acute Continuum - Lessons Learned from Geisinger’s ProvenHealth Navigator @ . Geisinger Health. February 3, 2012. Available from: https://www.eiseverywhere.com/file_uploads/02f7e4e31e9844738f3cf07556fdf051_Tomcavage.Janet.pdf

[21] ProMedica. ProMedica, HCR ManorCare Partner to Develop Skilled Nursing Facility and Rehabilitation Center. November 15, 2012. Available from: http://www.promedica.org/body.cfm?id=19\&action=detail\&ref=104

[22] Delivery of Post-Acute Care Services Among Leading Health Systems: A case study of current best practices - Executive Summary. National Rehabilitation Hospital and MedStar Heatlh. 2011.

[23] Partners HealthCare. Available from: http://www.partnersathome.org/index.aspx

[24] Feng Z, Lepore M, Clark MA, et al. Geographic Concentration and Correlates of Nursing Home Closures: 1999-2008. Arch Intern Med. 2011; 171(9): 806-813. PMid: 21220642. http://dx.doi.org/10.1001/archinternmed.2010.492

[25] Yue Li, Xueya Cai, Jun Yin, Laurent G Glance, Dana B Mukamel. Is Higher Volume of Postacute Care Patients Associated With a Lower Rehospitalization Rate in Skilled Nursing Facilities? Med Care Res Rev. 2012; 69: 103. PMid: 21810798. http://dx.doi.org/10.1177/1077558711414274

[26] Vincent Mor, Jacqueline Zinn, Joseph Angelelli, Joan M Teno, Susan C Miller. Driven to Tiers: Socioeconomic and Racial Disparities in the Quality of Nursing Home Care. The Milbank Quarterly. 2004; 82(2): 227-56. PMid: 15225329. http://dx.doi.org/10.1111/j.0887-378X.2004.00309.x

[27] Hospitals \& Health Networks Daily. Christopher Donovan and Adria Warren. New Models for Post-Acute Partnerships. 2013. Available from: http://www.hhnmag.com/display/HHN-news-article.dhtml?dcrPath=/templatedata/HF_Common/NewsArticle/data/HHN/Daily/ 2013/Sept/donovan092613-6190008949

[28] Centers for Medicare and Medicaid Services. Post-Acute Care Payment Reform Demonstration: Final Report. March 2012. Available from: http://www.cms.gov/Research-Statistics-Data-and-Systems/Statistics-Trends-and-Reports/Reports/Research-Reports-Items/PA C_Payment_Reform_Demo_Final.html

[29] Eric A Coleman, MD, MPH. Falling Through the Cracks: Challenges and Opportunities for Improving Transitional Care for Persons with Continuous Complex Care Needs. Journal of the American Geriatric Society. 2003; 51: 549-555. http://dx.doi.org/10.1046/j.1532-5415.2003.51185.x 